\title{
Age and Gender Difference in Antisocial Behavior among Adolescents' School Students
}

\section{Dr Roya Kavian Mobarake}

\author{
Faculty of Human Ecology, Universiti Putra Malaysia, Serdang, Selangor, Malaysia \\ Roya_kavian@yahoo.com
}

\author{
Doi:10.5901/mjss.2015.v6n4s2p194
}

\begin{abstract}
This study aims to examine the association between age, gender and antisocial behavior among 395 adolescents aged between 13 and 18 years in Tehran city in Iran. In this quantitative study, Pearson's product-moment correlation coefficient was applied to determine the relationship between the antisocial behavior of adolescents and age and gender. In addition, an independent sample t-test was used to compare the adolescent's antisocial behavior between male and female respondents. Results of this study indicated that there was a positive significant correlation between age and gender of respondents and antisocial behavior. Pearson correlation analysis showed a positive significant correlation between age of respondents and antisocial behavior. The finding of this study shows that older adolescents associated with more frequent of adolescent's antisocial behavior than younger adolescents. Furthermore, there was a difference in adolescent's antisocial behavior between male and female. These results indicated that the male is more likely to show antisocial behavior than female. By implication, the study contributes to existing literature in understanding the psychological development stage and age and gender as an important factors for adolescent development.
\end{abstract}

Keywords: Age, Male, Female, Antisocial Behavior, Adolescents

\section{Introduction}

In the last few decades, exploring the reasons and risk factors which are related to children's and adolescents' delinquent behavior has been of great importance in the relevant research area, possibly for two main reasons: the serious effects of antisocial behavior over time and its consequences on social and economic cost (Frick and Loney, 2002). In previous studies, it was found that antisocial behavior is multi-determined, that is the dysfunctions in children's behavior causes by inter acting a number of risk factors and not just influencing a single factor. They result in increasing aggressive and antisocial behavior in a child in a micro perspective view and in his social environment in the broader scale (Loeber et al. 2009).

The requirement for mental health services have been enhanced as delinquent behavior results in increasing various types of problems in societies (Frick et al., 2005). As a matter of fact, antisocial behavior as severe distress in communities starts manifesting in early stages of adolescence (Wright et al., 2007). NCES (2007) reported that 75\% of public schools in America encountered at least one violent or criminal action during $2007-2008$ academic years. A report highlights that $60 \%$ of children in the United States has exposed to direct or indirect scenes of violence (the National Center for Education Statistics [NCES], 2010). Moreover, Furthermore, the main crime investigation survey revealed that eight out of 10 people reported antisocial behavior has increased in England and Wales within the past year (Allen, Edmonds, Patterson, \& Smith 2006).

In addition, other studies indicated that especially, among African American adolescents, the risk of youth crimes such as high crime, unemployment, and vandalism has risen (Entner Wright \& Younts, 2009; Donnell, Richards, Pearced, \& Romero, 2012). Moreover, a majority of $80 \%$ of youth deviant happened when adolescents possessed four or more risk factors along with drinking alcohol in the past month and/or being engaged in antisocial behavior in the past year. These figures were diminished as the number of risk factors was decreased. For example, just more than $50 \%$ of adolescents who had two or three risk factors, and over $23 \%$ of those possessed one or no risk factors involved in antisocial behavior (Australian Research Alliance for Children and Youth, 2009). Similar to other parts of the world, in the context of this study, Iran, antisocial behavior has also been multiplied. For instance, 28,000 children and adolescents were in rehabilitation centers in Iran (Mohammadiasl, 2006). Therefore, it seems highly critical to explore causes and factors which can result in antisocial behavior among children and adolescents.

According to Fortin (2003), antisocial behavior describes as any violent behavior which breaches laws and people's right. Deviant behavior may be found in different forms such as vandalism (e.g., breaking trees, destroying bus 
seats or cutting public phone wires and writing on walls, chairs or desks), crime, assaults or other sorts of behavior which goes against the norms of in a society. Another common antisocial behavior is cultural misconduct such as receiving warnings by school officials due to breaking the school rules or, in an Islamic country such as Iran, warning from the police or school officials because of violating the Islamic covering codes. This study investigates the antisocial behavior which refers to a set of behavior conducted against social rules and norms such as vandalism and cultural misconduct as expressed earlier.

Several factors such as age and gender are associated with adolescent's antisocial behavior. Burt and Neiderhiser (2009) point out that age is one of the main characteristics which can determine antisocial behavior among children and adolescents. Moreover, Letourneau et al. (2013) suggest that age might be used as a moderator variable on the relationship between (SES) and delinquency. In contrast, age impact leads to decreasing environmental factors on antisocial behavior as shown in behavioral genetics research. According to Geolge (2012), the findings obtained from different studies on possible influence of gender on social problems are not consistent. There are some evidence for the specific impact of gender on relationship between behavior problems and delinquency among adolescents. In some of these studies, the effect of juvenile delinquency anticipated in boys whereas adult crimes as a type of antisocial behavior contributed to both genders. It is proposed that the influence of delinquent behavior in adolescents might be occurred with a delay in girls (Topitzes et al. 2011).

Furthermore, there were some visible results for adolescents' tendency for antisocial behavior. Various risk factors intervened delinquency and crimes happened by both genders. As such, adolescent boys were more eager to externalize antisocial behavior, school obligation, social-emotional skills, and school achievements. This could reveal the relationship between behavior problems and crime in adolescence period. On the contrary, parental factors, externalizing problems, cognitive process, and educational performance were more predicted in adolescent girls (Topitzes et al. 2011). Another research carried out by Foy et al. (2012) indicated that trauma, as consequences of delinquent behavior, has an effective role in increasing of antisocial behavior in girls than in boys. In fact, the effects of gender differences on the relationship between antisocial behavior and delinquency illustrated different mixed results.

Social control theory ascertains that the antisocial behavior in both genders would be rooted in learning processes taken place in their socializing environments such as their family, friends and schools. These models also explain the various rates of antisocial behavior in males and females which is considered as the gender gap in delinquency. Males actually possess more chances to learn and show antisocial behavior because of lower supervision by their families on them. This is the popular characteristics of conventional environments while highly conducting with unconventional groups. In addition, it is believed that social control theory (Hirschi, 1969) and the theory of crime (Gottfredson \& Hirschi, 1990) can explain the reasons for lower rates of delinquency in females as they traditionally have more attachment to conventional contexts, in particular to their families. This, in turn, leads to more commitment to conventional norms on the part of women in traditional settings. In contrast, results obtained from research on both genders inclined to deduce that due to higher exposure to risk factors for antisocial behavior such as higher contact with delinquent peers, lower parental monitor, less connection to family and school, males are more apt to involve in antisocial behavior (Elliot, Huizinga, \&Ageton, 1985; Storvoll \& Wichstrom, 2002).

Other studies, however, emphasize that to comprehend the role of gender in deviant behavior, it is inadequate to take in the samples from females to investigate and prove whether females replicate what are ascribed by males. As a matter of fact, it is crucial to suggest other models to take the existence of differential socialization routes into consideration. This fact can explain the influence of both possibilities, that is, unequal exposure of males to risk/protection factors and what helps to construct personal identities. These factors play a great role in varieties of performance for potentially antisocial behavior. Steffensmeier and Allan (1996) suggest a theoretical model in which the important concept is organization of gender. In other words, a series of factors that can cause differences in the social life structures of males and females such as gender norms, identity, affiliative concerns, and moral development are taken into account. The model determines fewer numbers of crimes committing by females.

The reason might refer to the feminine gender who assumes to engage in affection, caring others, and sustaining interpersonal relations. These aspects and concepts are not well-matched with delinquent and deviant behavior. On the contrary, the organization of males' identity is associated with some characteristics including competitiveness for attaining social positions. As such, a male person's own wishes and concerns precede others' wills, and thus, males become more appropriate and have more inclination and tendency for antisocial behavior. There are scant number of studies on correlation between age and gender identity and deviant behavior.

Referring to above mentioned relationship; Pearson correlation analysis was applied to determine relationship between age and gender and adolescent's antisocial behavior and independent sample t-test was applied to compare the antisocial behavior in males and females. In the related literature, the impact of gender identity on those variables which 
are relevant to adolescent deviation was investigated by using an independent t-test (López\& Rodríguez-Arias, 2010). The findings revealed that there was a significant relationship between age and gender on antisocial behavior among adolescents. Hence, this study also makes attempts to compare the differences of adolescents' deviant behavior in both genders, that is, males and females.

\section{Purpose of the Study}

The purpose of this study is to compare the difference between age and gender groups in antisocial behavior among adolescents in Tehran, Iran. Thus, the researcher proposed the following research hypotheses:

Ho1: Male adolescents involved more frequently in antisocial behavior compared to female adolescents in Tehran, Iran.

Ho2: Older adolescents involved more frequently in antisocial behavior compared to younger adolescents in Tehran, Iran.

\section{Method}

\subsection{Participants}

A total of 395 male and female adolescents were recruited from daily secondary and high schools in Tehran, Iran. The research applies cluster sampling as a sampling design. The participants were at the age of 13 to 18 . The mean age was 15 years with $\mathrm{SD}=1.44$.

\subsection{Measures}

\subsubsection{Age and Gender}

The participants' background information was collected by asking the students to tick the appropriate options in relation to their age and gender distribution under the demographic section in the questionnaire.

\subsubsection{Antisocial behavior}

Antisocial behavior was evaluated through a survey questionnaire regarding antisocial Behavior (Dekovic, 1999). Using 18 items, the scale focused on some minor acts entailing truancy, public transportation usage without paying, and some serious deviant acts, encompassing purposely beating someone or intentionally setting fires. These questionnaire was administrated to ask adolescents how often they commit these acts during the last 12 months: 0 for never, 1 representing once, 2 presenting two or three times, 3 stands for four to 10 times, and 4 representing more than 10 times. As the research was conducted in Iran, these three items were deleted, namely, using hard drugs such as heroin, using soft drugs such as cannabis, cocaine, speed and LSD; and being drunk. But replaced by seven additional items, namely, skipped school without giving a good excuse, steeling little things with lesser prices than five dollars, watched pornography, trespassed on people's property, wore clothes against school policy, arguing with the school principal or teacher, and fighting with classmates or other students in school. Addition of these seven items to questionnaire was based on prior studies and discipline principles effecting in Iran. Here, the total scale ranged from 0 to 88, thus, the higher scores represents a higher level of antisocial behavior. The questionnaire indicates an overall alpha of 0.94 for the total scale (Dekovic et al., 2004). The reliability value of the scale in the current study present an alpha coefficient of 0.79 indicating the scale is reliable.

\subsection{Procedure}

This study was authorized by Department of Education of Tehran. To select the participants, students with discipline problems were listed by assistance of the school counselor. The whole students listed here, participated in the survey.

\subsection{Statistical Analysis}

To describe the variables of the study, a descriptive statistical analysis including frequency, percentage, means, and 
standard deviations was employed. Furthermore, Pearson's product-moment correlation coefficient was also applied to determine the direction and strength of the linear relationship between the antisocial behavior of adolescents on age and gender. Independent sample t-test is utilized when there are two different (independent) groups of people (males and females) and researcher interested in comparing their scores. In this study independent sample t-test was performed to examine the gender differences in adolescent's antisocial behavior.

\subsubsection{Results}

As shown in Table 1, the measures applied in this survey indicated acceptable to excellent reliabilities ranging from 0.79 to 0.93 . The skewness and kurtosis values of the study variables were between -2 and +2 ; therefore, the assumption of normality has not been violated. Based on exploratory data analysis, for antisocial behavior the distribution of scores indicates a slight and positive skewness of 0.324 , and for gender it shows a slight and positive skewness of 0.076 , and for age the distribution of scores indicates a slight and positive of 0.181 , the variables of which were within acceptable limits and imminent to normal distribution.

Table 1. Assessment of Normality for Study Variables

\begin{tabular}{ccccc}
\hline \hline Instruments & Mean & 5\% trimmed mean & Skewness & Kurtosis \\
\hline Antisocial Behavior & 0.98 & 0.97 & 0.324 & -0.145 \\
Age & 15 & 15 & 0.181 & -.870 \\
\hline \hline
\end{tabular}

As shown in Table 2, the respondents of this study consisted of 205 (51.9 \%) males and $190(48.1 \%)$ females. The respondent's age ranged from 13 to 18 years with the mean and median age equal 15 and the standard deviation is 1.44. The majority (44.3\%) of respondents were between (15-16) years old. 32.2\% of adolescents were between 13-14 years old. About $23.5 \%$ of respondents were between (17-18) years old.

Table 2. Psychometric Properties of the Major Study Variables $(n=395)$

\begin{tabular}{cccccc}
\hline \hline Variables & $\mathrm{F}(\%)$ & Mean & SD & Min. & Max. \\
\hline $\begin{array}{c}\text { Antisocial Behavior } \\
\text { Low } \leq 20.95\end{array}$ & $193(48.9)$ & 20.95 & 9.54 & 0 & 48 \\
High $>20.96$ & $201(51.1)$ & & & & \\
Age & & 15 & 1.44 & 13 & 18 \\
$13-14$ & $127(32.2 \%)$ & & & & \\
$15-16$ & $175(44.3 \%)$ & & & & \\
$17-18$ & $93(23.5 \%)$ & & & & \\
Gender & & & & & \\
Male & $205(51.9)$ & & & & \\
Female & $190(48.1)$ & & & \\
\hline \hline
\end{tabular}

Note: Min= Minimum, Max= Maximum, SD= Standard Deviation, F = Frequency, SD = Standard deviation

As depicted in Table 3, an independent sample t-test was conducted to compare the adolescent's antisocial behavior between male and female respondents. There was a significant difference in adolescents antisocial behavior between male $(M=1.05, S D=0.39)$ and female $(M=0.85, S D=0.40) ; t(d f=393)=4.84, P \leq 0.01$. Therefore, Ho1 is supported. These results indicated that the male is more likely to show antisocial behavior than female. Similar to previous research (Crick, 1997; Spieker, Larson, Lewis, Keller, \& Gilchrist, 1999; Bongers, Koot, van der Ende \&Verhulst, 2003; Abdul Jalal, 2006; Aliverdinia, Sharehpoor\&Varmzyar, 2008; Miner \& Clarke-Stewart, 2008; Galloway, 2010) found that male adolescents have more frequent antisocial behavior compared to females. 
Table 3. Independent sample T-test for adolescents antisocial behaviour by gender

\begin{tabular}{|c|c|c|c|c|c|}
\hline \multirow[b]{2}{*}{ Variable } & \multicolumn{2}{|c|}{ Female $(n=190)$} & \multicolumn{2}{|c|}{ Male $(n=205)$} & \multirow[b]{2}{*}{ t-value } \\
\hline & Mean & SD & Mean & SD & \\
\hline Antisocial Behavior & .85 & 0.40 & 1.05 & 0.39 & $4.84^{\star \star}$ \\
\hline
\end{tabular}

The gender differences in the way antisocial behavior is expressed may be related to the differing rate of maturity between girls and boys (Dishion, French, and Patterson, 1995). According to the finding of this study, the boys antisocial behaviors are extremely pervasive than the girls in the southern parts of Tehran, Iran. It might be a reflection of the influence of the Iranians families on their children bringing up. Boys have more freedom in going and coming without being inspected by their families. Therefore, they have more chances to join with deviant peers and enjoy themselves with antisocial behaviors. These results are consistent with other research findings by some researchers such as Bongers, Koot, van der Ende, and Verhulst (2003) Miner and Clarke-Stewart (2008) who examine gender differences in adolescents and suggested that boys are more likely to exhibit problems, such as physically aggressive and conflicted interpersonal interactions than girls. Dishion et al. (1995) suggest that boys' behavioral problems are less stable than girls. Furthermore, research examining gender differences in adolescent antisocial behaviors has similarly found that adolescent boys are more physically aggressive, consumed more alcohol, and committed more property offenses than girls (Windle, 1990). Similarly, this finding also corresponds with other studies (Sobotkova et al., 2012) which confirmed that boys tend to behave more aggressively than girls and that antisocial behaviors gradually increase during adolescence.

Table 4. Relationship between adolescents' Age and antisocial behavior

\begin{tabular}{ccc}
\hline \hline & Variables & Antisocial behavior $(r)$ \\
\cline { 2 - 3 } & Age & $0.144^{* *}$ \\
\hline$\overline{01}$ & &
\end{tabular}

As shown in Table 4. Pearson correlation analysis showed a positive significant correlation between age of respondents and antisocial behavior $(r=0.144, p \leq 0.01)$. Therefore, $\mathrm{Ho} 2$ is supported. The finding of this study shows that older adolescents associated with more frequent of adolescent's antisocial behavior. These findings are consistent with previous research (Moffitt et al., 1996; Sohrabi et al., 2007) that found as age increase the probability of antisocial behavior increases. According to Piquero (2007) antisocial behavior and criminality activity increase during adolescence and peaks around age 17 and declines as individuals enter adulthood. There is a considerable literature on factors that contribute to the increase in antisocial behavior that takes place during adolescence (e.g., increases in vulnerability to peer pressure, decreases in parental monitoring). Patterson (1982) suggests that poor family functioning leads to impaired development of normal social skills and increased opportunity for involvement with deviant peers. Laird, Pettit, Dodge, \& Bates, (2003) explained that adolescence is characterized by an increased involvement with peers which also could shape what goes on in the family. Researchers (Montemayor, 1983; Stoolmiller, 1994) explained that regarding to pattern of change in relationship quality between parents and adolescents, they spend increasingly less time together as the child ages, there may be significantly lower levels of openness/ warmth and conflict/coercion in older youth compared to younger adolescents.

\section{Discussion and Conclusion}

This study investigated adolescents' age and gender and the adolescents' antisocial behavior in Tehran, Iran. The study found a significant association between older and male adolescents and antisocial behavior. This means, older adolescents more likely exhibit antisocial behavior than younger, and boys antisocial behaviors are extremely pervasive than the girls. Present study supported previous findings that male and older adolescents showed more frequent of antisocial behavior and delinquent act than younger and female adolescents. Society should take action to identify this violence earlier and protect them to delinquency and crime later. In terms of prevention of antisocial behavior among adolescents, it is important to be aware of male and older adolescents commit more offences against persons, whereas female adolescents offenders more commit aggressive and report of violence that are not include of any antisocial behavior. Given the association between age, gender and antisocial behavior for both girls and boys, younger or older, 
intervention could pay attention to potential effects of age and gender and to the assessment of violence and delinquent act in juvenile.

By implication therefore, the findings of this study fill the existing gap regarding this social issue in Iran and contribute to existing literature in terms of understanding psychological developmental stage and family context as important factors in adolescent development. Findings of this study will help the school and educational counselors who are more concerned about the adolescents' needs and protecting them against the effects of unhealthy families. Moreover, the information derived from the present research can significantly enable the educators to enhance their understandings of the crucial factors that involve in the development of antisocial behavior among adolescents. The results of this research also show the unique role of parents in the adolescents' antisocial behavior. Thus, the results benefit parents the most, so they can be aware of the factors contributing to their children's antisocial behavior. There are several limitations on this study. The first is the sample. The respondents in this study were adolescents in Tehran, Iran. Therefore, the results are not generalizable. The second one is that the study is cross-sectional. Thus, the long-term effect of family income on the behavior problems of adolescents cannot be examined.

\section{References}

Abdul-Jalal, F. H. (2006). Family functioning and adolescent delinquency in Malaysia. (Unpublished doctoral dissertation), lowa state university. Malaysia.

Allen, J., Edmonds, S., Patterson, A. and Smith, D. (2006) Policing and the criminal justice system - public confidence and perceptions: findings from the 2004/05 British Crime Survey. Home Office Online Report 07/06. London: Home Office.

Aud, S., Hussar, W., Planty, M., Snyder, T., Bianco, K., Fox, M., Frohlich, L., Kemp, J., Drake, L. (2010). The Condition of Education 2010. National Center for Education Statistics, Institute of Education Sciences, U.S. Department of Education, Washington, DC.

Belknap, J., \& Holsinger, K.R. (2006). The gendered nature of risk factors for delinquency. Feminist Criminology, 1(1), 48-71.

Bongers, I., Koot, H., van der Ende, J., \& Verhulst, F. (2003). The normative development of child and adolescent problem behaviour. Journal of Abnormal Psychology, 112, 179-192.

Burt, S. Alexandra; Neiderhiser, Jenae M.(2009). Aggressive versus nonaggressive antisocial behavior: Distinctive etiological moderation by age. Developmental Psychology, 45(4), 1164-1176. http://dx.doi.org/10.1037/a0016130

Burt, S.A. (2009). Are there meaningful etiological differences within antisocial behavior? Results of a meta-analysis. Clinical Psychology Review, 29 (2), 163- 178. http://dx.doi.org/10.1016/j.cpr.2008.12.004.

Crick, N. (1997). Engagement in gender normative verses non-normative forms of aggression: Links to social-psychological adjustment. Developmental Psychology, 33, 610-617.

Dekovic , M. (1999). Risk and protective factors in the development of problem behavior during adolescence. Journal of Youth and Adolescence, 28(6), 667-685.

Dekovic, M., Buist KL, Reitz E (2004) Stability and changes in problem behavior during adolescence: Latent growth analysis. Journal of Youth and Adolescence, 33:1-12.

Dishion, T. J., French, D. C., \& Patterson, G. R. (1995). The development and ecology of antisocial behaviour. In D. Cicchetti \& D. J. Cohen (Eds.), Developmental psycho-pathology (Vol. 2, pp. 421-471). New York: John Wiley \& Sons.

Elliot, D. S., Huizinga,D., \& Ageton, S.S. (1985). Explaining delinquency and drug use. Beverly Hills, CA: Sage.

Entner Wright, B. R., \& Younts, C. W. (2009). Reconsidering the relationship between race and crime: Positive and negative predictors of crime among African American youth. Journal of Research in Crime and Delinquency, 46, 327-352.

Fortin, L. (2003). Students' antisocial and aggressive behavior: development and prediction. Journal of Educational Administration, $41(6), 669-688$.

Foy, D. W., Ritchie, I. K., \& Conway, A. H. (2012). Trauma exposure, posttraumatic stress, and comorbidities in female adolescent offenders: findings and implications from recent studies. European Journal of Psych traumatology, 3, 17247. doi:I0.3402/ejpt.v3i0.

Frick ,P.J.\&Loney,B.R.(2002). Understanding the association between parent and child behavior. In R.J.McMahon\&R.Dcv.Peters (Eds.).The effects of parental dysfunction on children (pp.105- 126).New YORK. Plenum press.

Frick, P. J., Stickle, T. R., Dandreaux, D. M., Farrell, J. M., \& Kimonis, E. R. (2005). Callous- unemotional traits in predicting the severity and stability of conduct problems and delinquency. Journal of Abnormal Child Psychology, 33, 471-487.

Galloway,S.K. (2010). Ethnic differences in parenting and adolescence antisocail behaviour: The role of harsh discipline and parent support (Unpublished doctoral dissertation), University of Virginia, Richmond.

Geolge, T. P. (2012). School engagement and juvenile offending among maltreated youth who vary by race ethnicity, gender, and type of maltreatment. Olympia: Washington State Center for Court. Research Administrative Office of the Courts.

Geolge, T. P. (2012). School engagement and juvenile offending among maltreated youth who vary by race ethnicity, gender, and type of maltreatment. Olympia: Washington State Center for Court. Research Administrative Office of the Courts.

Gottfredson, M. R., \& Hirschi, T. (1990). A general theory of crime: Stanford University Press.

Hirschi, T. (1969). Causes of delinquency. Berkeley: University of California Press.

Laird, R. D., Pettit, G. S., Dodge, K. A., \& Bates, J. E, (2003). Change in parents' monitoring knowledge: Links with parenting, relationship quality, adolescent beliefs, and antisocial behavior. Social Development, 12, 401-419. 
Letourneau, N.L., Duffet-Leger, L., Levac, L., Watson, B., \& Young-Morris, C. (2013). Socio-economic status and child development: A meta-analysis. Journal of Emotional and Behavioral Disorders, 21 (3), 211 - 224. http://dx.doi.org/10.1177/10634266114

Loeber, R, Burlre, J.D.,\& Pardini, D.A. (2009). Development and etiology of disruptive and delinquent behavior. Annual Review of Clinical Psychology, 5,291- 310.doi:10.1146/annurev.clinpsy.032408.153631.

López, S., \& Rodríguez-Arias, J.L. (2010). Factores de riesgo y de protección en el consumo de drogas en adolescentes y diferencias según edad y sexo [Risk and protection factors in adolescents' drug consumption and age and sex differences]. Psicothema, 22(4), 568-573.

Miner, J. \& Clarke-Stewart, A. (2008). Trajectories of externalizing behaviour from age 2 to age 9: Relations with gender, temperament, ethnicity, parenting, and rater. Developmental Psychology, 44, 771-786.

Moffitt, T., Caspi, A., Dickson, N., Silva, P., \& Stanton, W. (1996). Childhood-onset versus adolescents-onset antisocial conduct problems in males: Natural history from ages 3 to 18 years. Development and Psychopathology, 8, 399-424.

Mohammadiasl, A. (2006). The dysfunction of family, school and peer -group and their effects on juvenile delinquency. Iran: Haghshenas.

Montemayor, R. (1983). Parents and adolescents in conflict: All of the families some of the time and some of the families most of the time. Journal of Early Adolescence, 3, 83-103.

O'Donnell,P., Richards,M., Pearce,S., Romero,E.(2012). Gender Differences in Monitoring and Deviant Peers as Predictors of Delinquent Behavior Among Low-Income Urban African American Youth. The Journal of Early Adolescence, 32(3) 431- 459.

Piquero AR. (2007). Taking stock of developmental trajectories on criminal activity over the life course. In A. Liberman,(Eds.), The long view of crime, A synthesis of longitudinal research. (pp. 23-78). New York, Springer.

Sobotkova, V., Batny, M., Jelinek, M., \& Hrdlic, M. (2012). Antisocial behavior in adolescence: Typology and relation to family context. Journal of Early Adolescence, xx(x),1-25.

Sohrabi, F., Hassani, A., (2007). Family factors, parenting style and adolescents antisocial behavior. Journal of Psychology , 11(1) 7588.

Spieker, S., Larson, N., Lewis, S., Keller, T., \& Gilchrist, L. (1999). Developmental trajectories of disruptive behaviour problems in preschool children of adolescent mothers. Child Development, 70, 443-458.

Steffensmeier, D., \& Allan, E. (1996). Gender and crime: Toward a gendered theory of female offending. Annual Review of Sociology, $22,459-487$.

Stoolmiller, M. (1994). Antisocial behavior, delinquent peer association and unsupervised wandering for boys: growth and change from childhood to early adolescence. Multivariate Behavioral Research, 29, 263- 288.

Storvoll, E., \& Wichstrom, L. (2002). Do the risk factors associated with conduct problems in adolescents vary according to gender? Journal of Adolescent, 25(2), 183-202.

Topitzes, J., Mersky, J. P., \& Reynolds, A. J. (2011).Child maltreatment and offending behavior: Gender-specific effects and pathways. Criminal Justice and Behavior, 38, 492-510. Doi: 10.1177/ 0093854811398578.

Windle, M. (1990). A longitudinal study of antisocial behaviours in early adolescence as predictors of late adolescent substance use: Gender and ethnic group differences. Journal of Abnormal Psychology, 99, 86-91.

Wright, R., John, L., Livingstone, A. M., Shepherd, N., \& Duku, E. (2007). Effects of school-based interventions on secondary school students with high and low risks for antisocial behaviour. Canadian Journal of School Psychology, 22(1), 32-49. 